\title{
Attenuation of the cytotoxic T lymphocyte response to lymphocytic choriomeningitis virus in mice subjected to chronic social stress
}

\author{
Annette Sommershof ${ }^{\mathrm{a}, *}$, Michael Basler ${ }^{\mathrm{a}, \mathrm{b}}$, Carsten Riether ${ }^{c}$, Harald Engler ${ }^{\mathrm{c}, \mathrm{d}, *, 1}$, Marcus Groettrup $^{\mathrm{a}, \mathrm{b}, 1}$ \\ a Division of Immunology, Department of Biology, Constance University, D-78457 Konstanz, Germany \\ ${ }^{\mathrm{b}}$ Biotechnology Institute Thurgau (BITg) at the University of Konstanz, CH-8280 Kreuzlingen, Switzerland

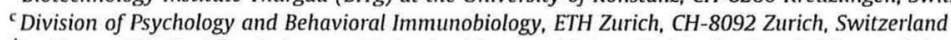 \\ ${ }^{\mathrm{d} I n s t i t u t e}$ of Medical Psychology and Behavioral Immunobiology, University Hospital Essen, University of Duisburg-Essen, D-45122 Essen, Germany
}

\begin{abstract}
A B S T R A C T
Chronic stress is suspected to increase the susceptibility to infections but experimental evidence from physiological stress models is scarce. We examined the effects of chronic social stress on virus-specific CTL responses in mice after infection with lymphocytic choriomeningitis virus (LCMV). Mice subjected to social stress on six consecutive days prior to infection showed a significant reduction of IFN- $\gamma$ producing $\mathrm{T}_{\mathrm{CD} 8}$ s splenocytes and markedly lowered plasma concentrations of IFN- $\gamma$. In contrast, the generation of LCMV-specific CTL responses was not altered in mice undergoing the same stress procedure concurrently with infection. Furthermore, stress exposure 6 days before and additional 3 days after LCMV infection profoundly reduced the expansion of $\mathrm{T}_{\mathrm{CD} 8+}$ cells in the spleen, due to diminished in vivo proliferation. Pharmacological blockade of glucocorticoid receptors completely abrogated the stress-associated decline of $\mathrm{T}_{\mathrm{CD} 8+}$ expansion. Stressed mice showed a significantly reduced expression of the early $\mathrm{T}$-cell activation marker CD69 as well as impaired in vitro cytokine secretion of IFN- $\gamma$ and IL-2. Additionally, social stress led to an altered migration capacity of $\mathrm{T}_{\mathrm{CD} 8}$, cells as demonstrated by adoptive $\mathrm{T}$ cell transfer experiments. Taken together, this study shows that chronic social stress fundamentally suppresses the functional capacities of T cells during a viral infection.
\end{abstract}

\section{Introduction}

Chronic stress increases the susceptibility to infectious diseases by affecting the function of cells of the innate and adaptive immune system. However, only few studies have investigated the effects of chronic stress on T cell-mediated immunity during viral infection. For example, mice exposed to chronic restraint displayed a decreased generation of virus-specific CTLS in response to primary HSV-1 infection (Bonneau et al., 1991a), and altered activation of $\mathrm{T}_{\mathrm{CD} 8_{+}}$memory cells (Bonneau et al., 1991b; Bonneau, 1996). However, most studies were performed using stressors without relevant behavioral context. Although these studies provided important insights into the immunmodulatory capacities of chronic stress, animal models of social stress are considered to

Abbreviations: LCMV, lymphocytic choriomeningitis virus; NP, nucleoprotein; GP, glycoprotein; SDR, social disruption stress.

* Corresponding authors. Address: Institute of Medical Psychology and Behavioral Immunobiology, University Hospital Essen, Hufelandstrasse 55, D-45122 Essen, Germany (H. Engler).

E-mail addresses: Annette.Sommershof@uni-konstanz.de (A. Sommershof), Harald.Engler@uk-essen.de (H. Engler).

1 These authors share senior authorship. be biologically more relevant, also with respect to stressful situations in humans. In this context, some recent studies examined the impact of social stress on the pathophysiological outcome of viral infections such as Theiler's virus (Johnson et al., 2004, 2006) and influenza virus (Sheridan et al., 2000) or mycobacterial BCG (bacillus Calmette-Guérin)-infection (Merlot et al., 2004) but very little is known about the impact of chronic social stress on $\mathrm{T}$ cell responses to viral infections.

A series of studies has investigated the consequences of repeated social stress exposure on $\mathrm{T}$ cell number and function. For instance, it has been demonstrated that social stress is accompanied by reduced numbers of $\mathrm{T}$ cells in the blood, spleen, and bone marrow of mice (Engler et al., 2004). Moreover, social defeat in rats led to decreased homing of adoptively transferred peripheral blood $\mathrm{T}$ cells into lymphoid organs, suggesting altered migration properties (Stefanski et al., 2003). Finally, it has been reported that social stress influences proliferation, cytokine production and $\mathrm{T}$ cell mediated cytotoxicity. For example, socially stressed mice exhibit suppressed $\mathrm{T}$ cell proliferation responses to the mitogen ConA and increased production of IL-6 and IFN- $\gamma$ as well as decreased production of IL-10 (Merlot et al., 2004). 
To analyze the effects of chronic social stress on an anti-viral T cell response, we performed a systemic infection using lymphocytic choriomeningitis virus (LCMV). LCMV is a natural mouse pathogen inducing a strong cytotoxic T cell $(\mathrm{CTL})$ response that is responsible for virus elimination. The CTL response of C57BL/6 mice is focused on the three dominant GP33-41/D $\mathrm{D}^{\mathrm{b}}$, GP34-41/K and NP396-404/D as well as several sub-dominant (GP276-286/ $\mathrm{D}^{\mathrm{b}}, \mathrm{GP} 92-101 / \mathrm{D}^{\mathrm{b}}, \mathrm{GP} 118-125 / \mathrm{K}^{\mathrm{b}}$ and NP205-212/K ) T cell epitopes (Gallimore et al., 1998; vanderMost et al., 2003). In addition, antigen processing and $\mathrm{T}$ cell epitope production are well characterized in the LCMV infection model and therefore it represents an optimal model to study potential $\mathrm{T}$ cell alterations in response to social stress.

In the present study we provide evidence that chronic social stress compromises the activation, expansion, and migration of LCMV-specific $\mathrm{T}_{\mathrm{CD} 8+}$ cells in the spleen. We further show that glucocorticoids play a fundamental role in these alterations by intrinsically inhibiting $\mathrm{T}_{\mathrm{CD} 8+}$ cell cytokine production and proliferation.

\section{Materials and methods}

\subsection{Experimental animals}

Male C57BL/6 mice $\left(\mathrm{H}-2^{\mathrm{b}}\right)$ as well as B6.SJL-PtprcaPep3b/BoyJ (also referred to as "Ly5.1 congenic mice") used in this study were originally obtained from Charles River Laboratories. B6.PL (Thy1.1) mice were obtained from The Jackson Laboratory (Bar Harbor, ME). Experimental mice were used at 7-8 weeks of age and were kept in a specified pathogen-free facility on a $12 / 12 \mathrm{~h} \mathrm{light/dark}$ cycle with ad libitum access to food and water. Both stressed and control mice were housed in groups of 5 mice per cage. All animal experiments were approved by the reviewing board of the Regierungspräsidium Freiburg.

\subsection{Stress procedure}

The social disruption (SDR) procedure was previously described (Engler et al., 2005; Avitsur et al., 2001; Stark et al., 2001). The stress paradigm is based on the disruption of an established social hierarchy of group-housed male mice (residents) which is experimentally induced by daily confrontations with an unfamiliar aggressive intruder mouse. For the stress procedure, an intruder was introduced into the residents cage for $2 \mathrm{~h}$ daily over a period of six (experiment 1 ) or nine (experiment 2) consecutive days. To prevent habituation, a different aggressor was used for each stress cycle. The stress procedure always started at the beginning of the dark period when animals display increased activity and naturally rising glucocorticoid levels. Control mice were left undisturbed in their home cages throughout the entire experiment.

\subsection{Administration of hormone receptor antagonists}

Mice were subcutaneously implanted with time release pellets (Innovative Research of America, Sarasota, FL) containing either $0.5 \mathrm{mg}$ of the non-selective $\beta$-adrenergic receptor antagonist nadolol (21-day release) or $30 \mathrm{mg}$ of the glucocorticoid type II receptor antagonist RU486 (12-day release). The pellets were implanted in the neck region of the animals 2 days prior to the stress procedure under ketamine/xylazine anaesthesia. Placebo pellets comprising only the inert carrier substance were used as a control. The optimal drug dosage for RU486 was determined in a preliminary experiment based on the ability to effectively prevent stress-induced thymic atrophy.

\subsection{Viruses and media}

LCMV-WE was obtained originally from F. Lehmann-Grube (Heinrich Pette Institute, University of Hamburg, Germany) and propagated on the fibroblast line L929. Mice were infected i.v. with $200 \mathrm{pfu}$ of LCMV-WE. All media were purchased from Invitrogen Life Technologies (Karlsruhe, Germany) and were supplemented with $5 \%$ or $10 \% \mathrm{FCS}$, and $100 \mathrm{U} / \mathrm{ml}$ penicillin/streptomycin.

\subsection{Intracellular staining (ICS) for IFN- $\gamma$ and flow cytometry}

ICS and flow cytometric analyses were performed as outlined previously (Basler et al., 2006). The following anti-mouse mAbs were used: $\operatorname{CD} 8 \alpha$ (clone 53-6.7), CD69 (clone H1.2F3), Thy1.2 (clone 53-2.1), CD11c (clone HL3), CD86 (clone B7-2), CD80 (clone
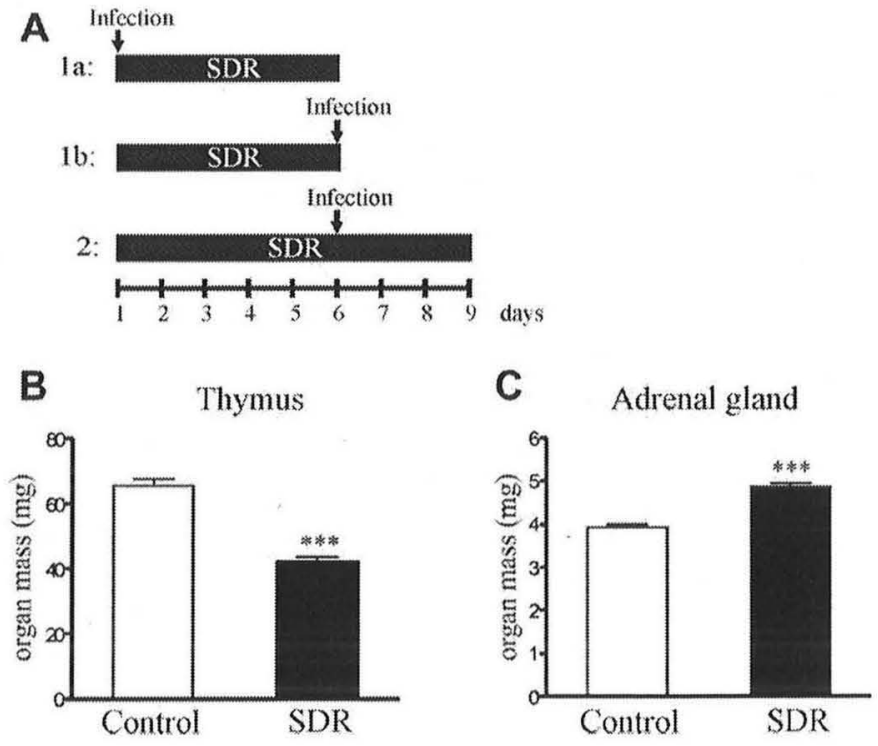

Fig. 1. Social disruption stress (SDR) caused thymic atrophy and adrenal hypertrophy. (A) Scheme of the experimental design. (B and C) Organ masses of thymus (B) and adrenal glands $(C)$ after six consecutive days of SDR. Graphs represent data from two independent experiments with a total of 9-10 mice per group (mean \pm SEM). 


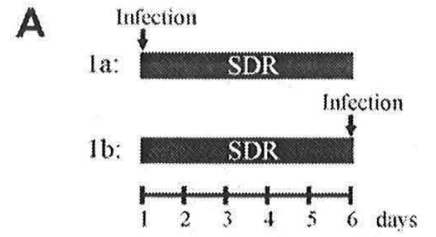

B
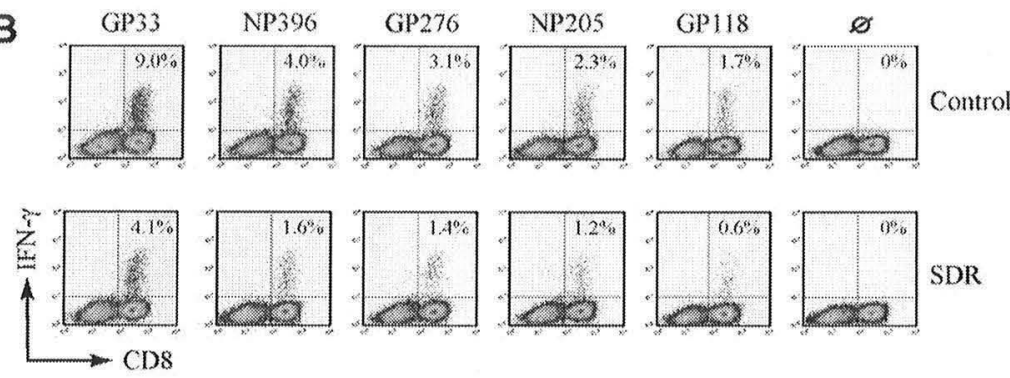

C

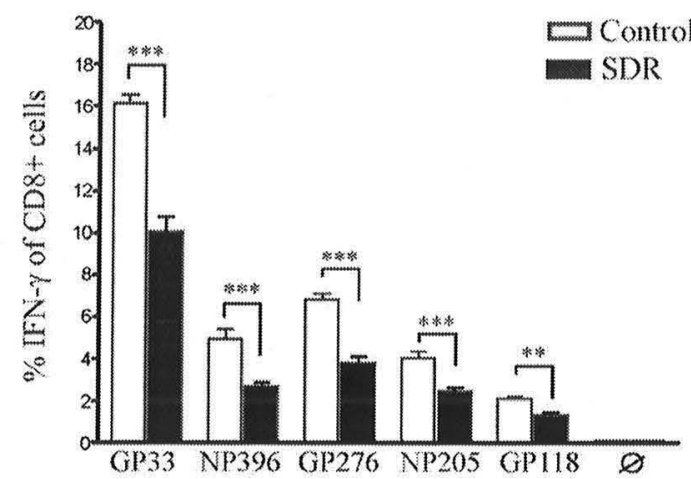

D

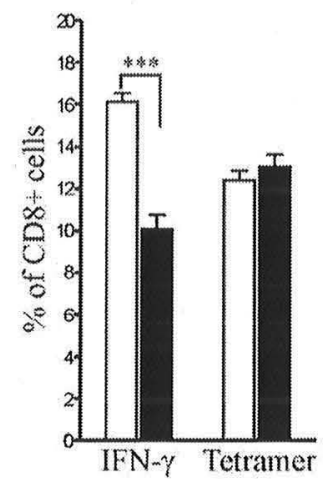

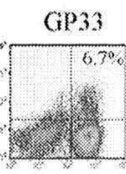
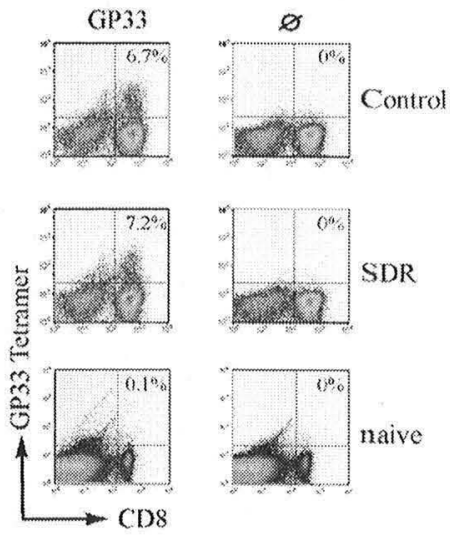

$E$

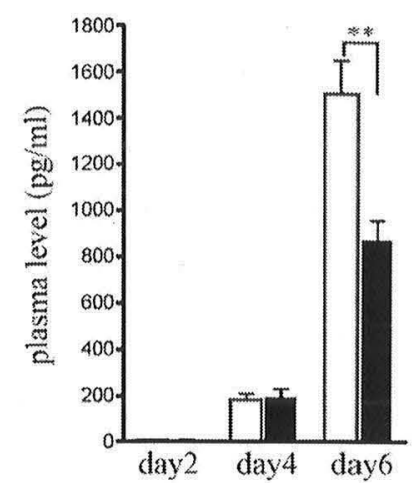

Fig. 2. Epitope-specific CTL responses in LCMV-infected control and SDR mice. (A) Scheme of the experimental design. Mice were subjected to 6 days of SDR and were subsequently infected with 200 pfu LCMV i.v.. (B, C, and D) Epitope-specific T $\mathrm{T}_{\mathrm{CD}}$ + cell responses were quantified on day 8 after infection by ICS (C) and tetramer staining (D). (B) Representative FACS plots of IFN- $\gamma$ ICS and tetramer staining are illustrated for SDR and control mice. $\varnothing$ represents background values of splenocytes without peptide stimulation (ICS) or splenocytes that were not labeled with peptide-MHC tetramers; 'naïve' sample represents tetramer staining of non-infected mice. (C) Percentage of IFN- $\gamma$ secreting $\mathrm{T}_{\mathrm{CD} 8+}$ cells from LCMV-infected SDR and control mice after $5 \mathrm{~h}$ of in vitro re-stimulation in the presence of the indicated peptides. (D) Production of IFN- $\gamma$ by GP33specific $\mathrm{T}_{\mathrm{CD8}+}$ cells after peptide-stimulation is compared with the percentage of CD8 ${ }^{+} / G P 33-$ tetramer+ cells. (E) Plasma levels of IFN- $\gamma$ in LCMV-infected SDR and control mice. On day 2, 4, and 6 post-infection peripheral blood was taken from SDR and control groups and IFN- $\gamma$ levels were determined using a bead-based assay. Graphs represent data from two independent experiments with a total of 9-10 mice per group (mean \pm SEM)

B7-1), H-2D ${ }^{\mathrm{b}}$ (clone KH95), H-2K ${ }^{\mathrm{b}}$ (clone AF6-88.5), CCR7 (clone 4B12), Ly5.2 (clone 104), F4/80 (clone BM8).

\subsection{BrdU in vivo proliferation assay}

For the determination of $\mathrm{T}_{\mathrm{CD} 8+}$ splenocyte proliferation, mice were injected intraperitoneally with $1 \mathrm{mg}$ of the thymidine analogue BrdU (Sigma) on day 5 post LCMV infection. Twenty-four hours later, splenocytes were stained for $20 \mathrm{~min}$ at $4{ }^{\circ} \mathrm{C}$ with anti-CD8 $\alpha$. Incorporation of BrdU was assessed by intracellular staining with FITC-conjugated mouse anti-BrdU by using the FITC BrdU Flow Kit (BD PharMingen) according to the manufacturer's instructions.

\subsection{Antigen-presentation assay}

Splenocytes from day 4 post-infection were used as stimulators in an antigen-presentation assay. LCMV GP33-specific CTL lines were generated from Thy1.1 mice as previously described (Basler et al., 2006). CTLs were used in the antigen-presentation assay at an effector-to-stimulator $(\mathrm{E}: \mathrm{S})$ ratio of $1: 6$ in the first dilution, and serial 3-fold dilutions of stimulators were performed. In a second approach, GP33-pulsed splenocytes from control or SDR-mice were used as stimulator cells for GP33-specific CTLs. Briefly, splenocytes were pre-incubated with different concentrations of GP33-peptide $\left[10^{-7}-10^{-11} \mathrm{M}\right]$ for $1 \mathrm{~h}$ at $37^{\circ} \mathrm{C}$ and washed three times with PBS. $3 \times 10^{6}$ stimulator cells were incubated in round-bottom 96-well plates with $5 \times 10^{5}$ CTLs in $200 \mu \mathrm{L}$ IMDM $10 \%+$ brefeldin A (BFA) $(10 \mu \mathrm{g} / \mathrm{mL})$ for $4 \mathrm{~h}$ at $37^{\circ} \mathrm{C}$. The staining, fixation and permeabilization of the cells were performed as detailed for the ICS IFN- $\gamma$.

\subsection{Adoptive $T$ cell transfer}

Spleen cells were collected from control and SDR mice on day 6 post-infection and T cells were purified by negative selection with the Pan T cell isolation kit (Miltenyi Biotec, Bergisch Gladbach, Germany). LCMV-infected (day 6 post-infection) Ly5.1 mice were used as recipients. A total of $1 \times 10^{7}$ mixed T cells from control $\left(5 \times 10^{6}\right)$ and SDR $\left(5 \times 10^{6}\right)$ mice were intraperitoneally (i.p.) or intravenously (i.v.) transferred in a ratio of $1: 1$ into Ly5.1 recipient mice. To ensure co-injection of equal numbers of $T_{\mathrm{CD} 8+}$ cells from 


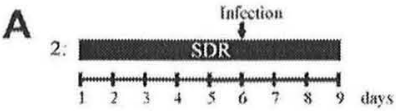

B

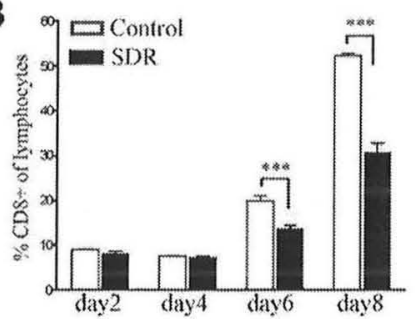

E

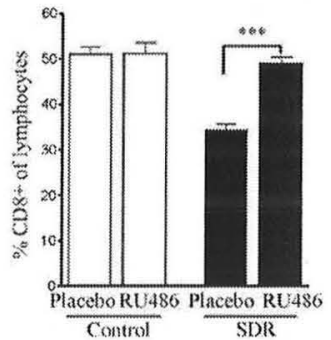

C

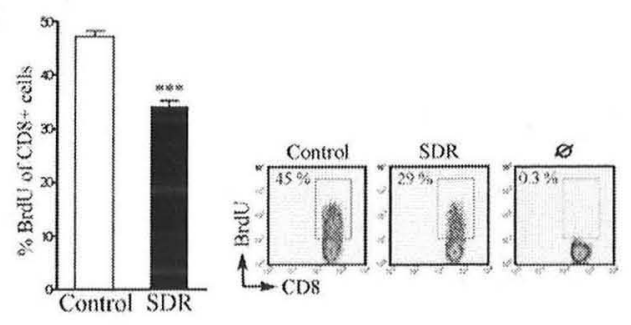

D

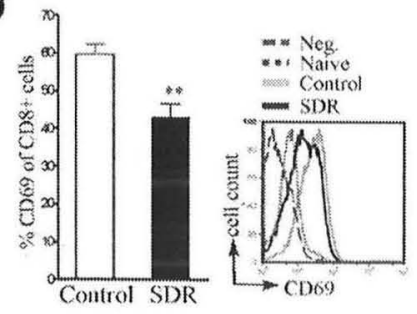

F

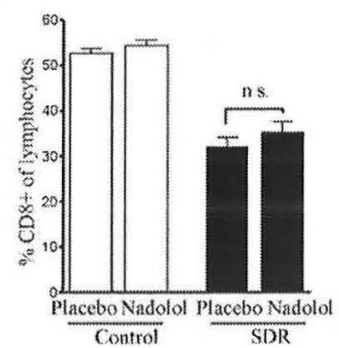

G

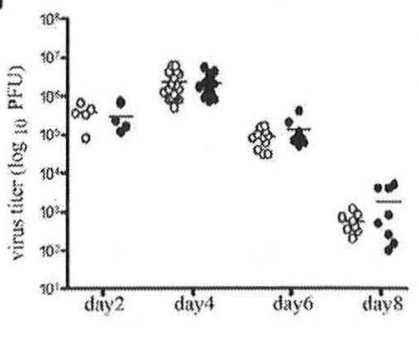

Fig. 3. Effects of an extended stress protocol on $\mathrm{T}_{\mathrm{CD} 8+}$ cell expansion in control and SDR mice. Mice remained undisturbed or were subjected to 6 days of SDR, then infected with 200 pfu of LCMV i.v., and SDR mice were stressed for additional 3 days post-infection. (A) Scheme of the experimental design. (B) The percentage of $T_{C D 8}$ lyınphocytes was determined on days $2,4,6$, and 8 post LCMV infection by flow cytometry. (C) Reduced $T_{C D 8}$ + proliferation in LCMV-infected SDR mice compared to control mice. On day 5 after LCMV infection, both groups received an in vivo pulse labelling with BrdU. Twenty-four hours after BrdU injection, spleens were removed and BrdU incorporation was assessed by flow cytometry after CD8 surface staining and intracellular staining for BrdU. Representative BrdU pulse profiles are illustrated for SDR and control mice obtained at day 6 of LCMV-infection. represents background values of splenocytes from mice that did not receive BrdU injection. (D) CD69 surface expression on $T_{C D 8}$, splenocytes in SDR compared to control mice. On day 2 post-infection $\mathrm{T}_{\mathrm{CD} 8}$ + splenocytes were analyzed for CD69 surface expression by flow cytometry. The histogram represents CD69 expression of $\mathrm{T}_{\mathrm{C} \dot{8} 8+}$ splenocytes from SDR (black line) and control (grey line) mice compared to non-infected naïve mice (dotted line). The negative control represents background values of the $\mathrm{T}_{\mathrm{CD} 8}$ + splenocyte population that was not stained for CD69 (dashed line). Data are presented as the mean percentage of CD69-positive cells \pm SEM of $T_{\mathrm{CD},}$, cell population. ( $\mathrm{E}$ and F) $\mathrm{T}_{\mathrm{CD} 8}$, cell expansion on day 8 post-infection in SDR and control mice treated with slow-release pellets of RU-486 (E), nadolol (F) or placebo. Data are presented as the mean percentage of $\mathrm{T}_{\mathrm{CD} 8+}$-positive cells SEM of the lymphocyte population. Two-factor ANOVA revealed a significant stress $\times$ drug interaction for RU486 ( $p<0.001)$. All graphs represent data from two independent experiments with a total of 9-10 mice per group. (G) Effects of SDR on viral titers in the spleen of LCMVinfected mice. On days $2,4,6$, and 8 post-infection, virus titers were determined in the spleen. Viral titers are shown as $\log _{10}$ plaque forming units (pfu) per spleen. Symbols represent individual mice; horizontal lines indicate mean values.

each donor, the ratio of $\mathrm{T}_{\mathrm{CD} 8+}$ cells was analyzed by flow cytometry before transfer. The ratio of recovered donor derived cells (control $^{\text {Ly5.2+, Thy 1.1+ }}$ SDR ${ }^{\mathrm{Ly} 5.2+}$, Thy1.2+ $)$ in the spleen, LN and blood was analyzed $24 \mathrm{~h}$ after the transfer by flow cytometry.

\subsection{Determination of cytokine levels}

IFN- $\gamma$ was quantified in the plasma using a commercially available bead-based assay (Bio-Plex Mouse IFN- $\gamma$ Assay, Bio-Rad Laboratories, Reinach, Switzerland). Spleens were collected on day 4 post-infection, and $4 \times 10^{5}$ splenocytes or magnetically enriched $\mathrm{T}_{\mathrm{CD} 8+}$ cells were stimulated in $200 \mu \mathrm{I}$ IMDM $10 \%$ for $24 \mathrm{~h}$ with $5 \mu \mathrm{g} / \mathrm{ml}$ coated anti-mouse CD3/CD28 mAb (clone 145-2C11, clone 37.51; $\mathrm{BD}$ ) in flat-bottom 96-well plates. The supernatants were analyzed for IFN- $\gamma$ and IL-2 secretion in triplicates using ELISA kits for murine IFN- $\gamma$ and IL-2 according to the manufacturer's instructions (BD).

\subsection{Virus titer}

To determine viral clearance, spleens were removed on day 2, 4, 6 and 8 post-infection, homogenized in MEM containing 5\% FCS and stored at $-80^{\circ} \mathrm{C}$. Supernatants were titrated by 10 -fold serial dilutions onto monolayers of the MC57 fibroblast line. LCMV infected MC57 cells were detected after $48 \mathrm{~h}$ of incubation at $37^{\circ} \mathrm{C}$ by immunofocus assay using the LCMV NP-specific mAB (VL-4) as previously described (Battegay et al., 1991).

\subsection{Purification of 205 proteasome from mouse organs and fluorogenic assay}

The proteasome purification procedure and subunit analysis by NEPHGE/SDS-PAGE was performed as described previously (Groettrup et al., 1995).

\subsection{Statistical analysis}

Data are expressed as mean \pm S.E.M. Means of two independent groups were analyzed using Student's $t$-test for independent pairs. Two-factor ANOVA was used to test for the effects of stress and drug treatment as well as the interaction of both factors. The levels of significance were set at $p<0.05(*), p<0.01(* *)$ and $p<0.001$ $(* * *)$. All statistics were calculated using GraphPad InStat 3 for Windows (GraphPad Software, La Jolla, CA).

\section{Results}

\subsection{Experimental design}

To analyze the impact of social disruption stress on the LCMVspecific CTL response, we compared different stress protocols (Fig. 1A). In a first trial, the stress procedure was either applied concurrently with LCMV infection (experiment 1a) or the experimental mice were first subjected to the stressor and received the 
infection afterwards (experiment $1 \mathrm{~b}$ ). In a second set of experiments, we examined the effect of a prolonged stress procedure on the outcome of LCMV infection, including $T$ cell expansion and migration as well as antigen presentation. For this purpose, mice were exposed to six consecutive days of SDR followed by LCMV infection and three additional days of SDR (experiment 2).

\subsection{Thymus atrophy and adrenal hypertrophy}

Organ masses of thymus and adrenal glands were determined after 6 days of SDR (Fig. 1B and C). Repeated exposure to the social stressor resulted in atrophy of the thymus and hypertrophy of the adrenals as shown by a significant reduction of thymus mass (SDR: $42.63 \pm 1.13 \mathrm{mg}$ vs. control: $65.68 \pm 2.0 \mathrm{mg}$ ) and a marked enlargement of the adrenal glands (SDR: $4.9 \pm 0.1 \mathrm{mg}$ vs. control: $3.9 \pm 0.1 \mathrm{mg}$ ). Both thymic atrophy and adrenal hypertrophy are consequences of frequent or persistent adrenocortical activation and are classical indicators of chronic stress (Engler et al., 2005).

\subsection{Effects of social stress on the LCMV-specific T cell response}

In a first set of experiments (Fig. 2A), the effect of SDR on the LCMV-specific CTL response was examined in two different timing schedules, comparing the impact of a 6-day stress procedure applied prior to virus infection (experiment $1 \mathrm{~b}$ ) with an experimental set-up in which SDR was administered concurrently with the infection (experiment 1a). At the peak of the primary response (day 8), intracellular cytokine staining was performed to determine the frequency of IFN- $\gamma$ producing $\mathrm{T}_{\mathrm{CD} 8}+$ cells specific for five defined LCMV epitopes: two dominant (GP33-41/D $/ \mathrm{D}^{\mathrm{b}} / \mathrm{K}^{\mathrm{b}}$ and NP396-404/ $\mathrm{D}^{\mathrm{b}}$ ) and three sub-dominant epitopes (GP276-286/D , GP118$125 / K^{\mathrm{b}}$ and NP205-212/Kb).

Mice that were subjected to social stress prior to virus infection (experiment $1 \mathrm{~b}$ ) exhibited a significant reduction of IFN- $\gamma$ producing $\mathrm{T}_{\mathrm{CD} 8}$. cells specific for the dominant LCMV epitopes GP33-41/ $\mathrm{D}^{\mathrm{b}} / \mathrm{K}^{\mathrm{b}}$ (SDR: $10.0 \pm 0.7 \%$ vs. control: $16.1 \pm 0.4 \%$ of total $\mathrm{T}_{\mathrm{CD} 8+}$ cells $)$ and NP396-404/D $\mathrm{D}^{\mathrm{b}}$ (SDR: $2.7 \pm 0.2 \%$ vs. control: $4.9 \pm 0.5 \%$ ) as well as the sub-dominant epitopes GP276-286/D ${ }^{\mathrm{b}}$ (SDR: $3.8 \pm 0.3 \%$ vs. control: $6.8 \pm 0.3$ ), NP205-212/K (SDR: $2.5 \pm 0.2 \%$ vs. control: $4.1 \pm 0.3$ ), and GP118-125/K $\mathrm{K}^{\mathrm{b}}$ (SDR: $1.4 \pm 0.2 \%$ vs. control: $2.1 \pm 0.1$ ) compared to control mice (see Fig. $2 \mathrm{~B}$ and $\mathrm{C}$ ). We further compared the frequency of IFN- $\gamma$ producing $\mathrm{T}_{\mathrm{CD} 8+}$ cells specific for the LCMV epitope GP33-41/D $/ \mathrm{K}^{\mathrm{b}}$ with the quantification of GP33specific $\mathrm{T}_{\mathrm{CD} 8+}$ cells by MHC-tetramer staining. As shown in Fig. 2D, SDR mice exhibited similar percentages of $\mathrm{T}_{\mathrm{CD} 8+/ \mathrm{GP} 33 \text {-tetramer }}{ }^{+}$cells compared to control mice (SDR: $13.0 \pm 0.6 \%$ vs. control: $12.4 \pm 0.5 \%$ of total $\mathrm{T}_{\mathrm{CD} 8+}$ cells). These data suggest that a large fraction of expanded $\mathrm{T}_{\mathrm{CD} 8+}$ cells fail to differentiate into effector cells that produce IFN- $\gamma$ upon stimulation, indicating that SDR profoundly impacts the function of splenic $\mathrm{T}_{\mathrm{CD} 8+}$ cells by inhibiting antigen-specific IFN- $\gamma$ secretion.

In contrast, the LCMV-specific CTL response was not significantly altered in mice receiving the same stress procedure concurrently with the infection (experiment $1 \mathrm{a}$ ). The frequency of IFN- $\gamma$ producing $\mathrm{T}_{\mathrm{CD} 8+}$ cells specific for GP33-41/D $/ \mathrm{D}^{\mathrm{b}} / \mathrm{K}^{\mathrm{b}}$ (SDR: $8.5 \pm 0.2 \%$ vs. control: $7.0 \pm 0.8 \%$ ), NP396- $404 / \mathrm{D}^{\mathrm{b}}$ (SDR: $6.2 \pm 0.5 \%$ vs. control: $4.8 \pm 0.7 \%$ ) and GP276-286/D ${ }^{\mathrm{b}}$ (SDR: $3.8 \pm 0.2 \%$ vs. control: $3.2 \pm 0.2 \%$ ) were not significantly increased.

\subsection{Effects of social stress on plasma IFN- $\gamma$ levels in LCMV-infected mice}

We further determined plasma levels of IFN- $\gamma$ in SDR and control mice on days 2,4 , and 6 post LCMV infection. As shown in Fig. $2 \mathrm{E}$, plasma concentrations of IFN- $\gamma$ increased gradually in both groups during the course of LCMV infection. However, while the concentration of IFN- $\gamma$ was not altered in SDR mice on day 4 post-infection, we observed an almost $50 \%$ reduction in circulating IFN- $\gamma$ levels on day 6 of infection (SDR: $871 \pm 86 \mathrm{pg} / \mathrm{ml}$ vs. control: $1505 \pm 145 \mathrm{pg} / \mathrm{ml}$ ) compared to controls.

\subsection{Prolonged stressor exposure leads to reduced expansion of $\mathrm{T}_{\mathrm{CD} 8+}$ splenocytes}

During the course of an LCMV infection, $\mathrm{T}_{\mathrm{CD} 8+}$ lymphocytes undergo multiple cycles of cell division after exposure to the antigen, as indicated by a progressive increase of the $\mathrm{T}_{\mathrm{CD} 8+}$ population within 8 days. Prolongation of the stress procedure for three additional days after LCMV infection caused a pronounced reduction of $\mathrm{T}_{\mathrm{CD} 8+}$ cells in the spleen of SDR mice on day 6 (SDR: $13.8 \pm 0.6 \%$ vs. control: $19.9 \pm 1.0 \%$ of splenocytes) and day 8 (SDR: $30.8 \pm 2.0 \%$ vs. control: $52.3 \pm 0.4 \%$ ) of infection (Fig. $3 \mathrm{~B}$ ). In contrast, there were no significant differences in the $\mathrm{T}_{\mathrm{CD} 8+}$ population on day 2 (SDR: $8.2 \pm 0.4 \%$ vs. control: $9.1 \pm 0.2 \%$ ) and day 4 (SDR: $7.4 \pm 0.1 \%$ vs control: $7.6 \pm 0.1 \%$ ) after infection, indicating that the alterations occur during the antigen-driven $\mathrm{T}$ cell expansion phase and are not due to initially reduced $\mathrm{T}_{\mathrm{CD} 8+}$ cell numbers. Moreover, stressed mice exhibited a significant reduction of epitope-specific IFN- $\gamma$ producing $\mathrm{T}_{\mathrm{CD} 8+}$ cells among total lymphocytes as analyzed by ICS, indicating that the overall reduction of $\mathrm{T}_{\mathrm{CD} 8}$ + cells in SDR mice reflects a diminished $\mathrm{LCMV}$-specific $\mathrm{T}_{\mathrm{CD} 8+}$ cell expansion (data not shown).

In contrast to the profound reduction of splenic $\mathrm{T}_{\mathrm{CD} 8+}$ cells, alterations in the LN were much less pronounced (SDR: $29.4 \pm 0.7 \%$ vs. control: $32.3 \pm 0.9 \%$ of splenocytes; $p \leqslant 0.05$ ), whereas no differences were observed in the blood (SDR: $55.8 \pm 1.9 \%$ vs. control: $56.7 \pm 2 \%$ ), liver (SDR: $47.2 \pm 0.5 \%$ vs. control: $48.9 \pm 2.2 \%$ ) or lung (SDR: $54.8 \pm 2.6 \%$ vs. control: $55.2 \pm 3.8 \%$ ).

\subsection{Social stress affects the proliferation capacity of $\mathrm{T}_{\mathrm{CD} 8_{+}}$lymphocytes}

To determine whether the decreased $\mathrm{T}_{\mathrm{CD} 8+}$ cell expansion found in SDR mice is due to a higher propensity of $T_{C D 8}$, cells to undergo apoptosis, we performed stainings with Annexin $\mathrm{V}$ and propidium iodide (PI). The frequency of early (Annexin $\left.\mathrm{V}^{+} / \mathrm{PI}^{-}\right)$and late (Annexin $\mathrm{V}^{+} / \mathrm{PI}^{+}$) apoptotic cells was determined by flow cytometry on days 2 and 8 post-infection. Analyses revealed no differences in the frequency of $\mathrm{T}_{\mathrm{CD} 8+}$ cells and total splenocytes undergoing apoptosis between SDR mice and non-stressed control mice (Supplementary Table I).

To further examine the deficit in $\mathrm{T}_{\mathrm{CD} 8+}$ cell expansion, we analyzed in vivo $\mathrm{T}$ cell proliferation by performing a BrdU pulse-labeling assay. Mice were treated with $1 \mathrm{mg}$ BrdU i.p. on day 5 of LCMV infection and BrdU incorporation in splenocytes was assessed by intracellular staining $24 \mathrm{~h}$ later. Analysis of BrdU staining in control mice demonstrated that approximately $50 \%$ of $\mathrm{T}_{\mathrm{CD} 8+}$ cells divide between day 5 and day 6 of LCMV infection (Fig. 3C). In contrast, the frequency of BrdU positive $\mathrm{T}_{\mathrm{CD} 8+}$ splenocytes in SDR mice was significantly reduced by $28 \%$ (SDR: $34.2 \pm 1.0 \%$ vs. control: $47.2 \pm 1.1 \%$ of $\mathrm{T}_{\mathrm{CD} 8}+$ cells). Our findings strongly suggest that the massive decrease in $\mathrm{T}_{\mathrm{CD} 8+}$ splenocyte expansion observed in SDR mice is predominantly a result of diminished proliferation capacity rather than an altered death rate of $\mathrm{T}_{\mathrm{CD} 8+}$ cells.

\subsection{Stress reduces expression of the T-cell activation marker CD69} on $\mathrm{T}_{\mathrm{CD} 8+}$ cells

Next, we investigated whether the reduced proliferation of $\mathrm{T}_{\mathrm{CD} 8+}$ cells is accompanied by inefficient T-cell activation. Therefore, we quantified the expression of different T-cell activation markers throughout the early stage of LCMV infection by flow cytometry. Our data revealed that SDR and control mice exhibited 
A

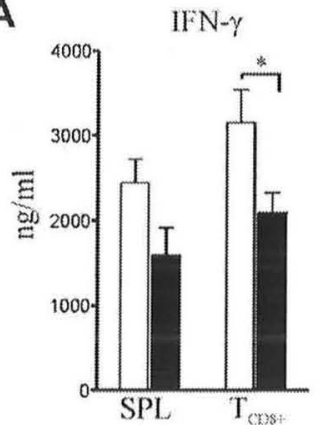

II.-2

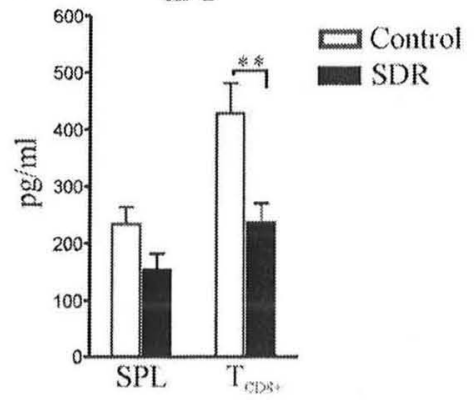

B

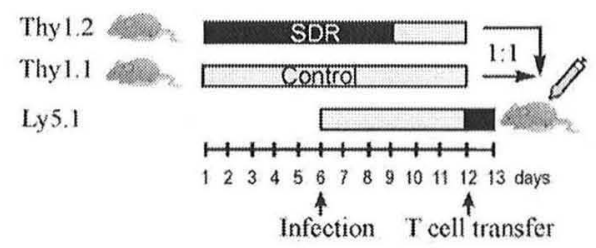

C

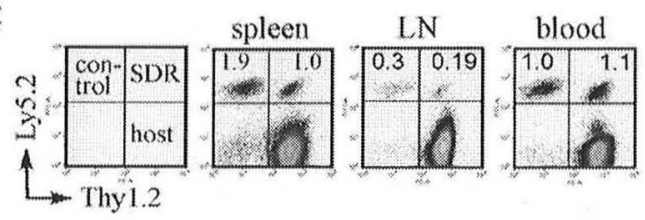

D $\square$ Control

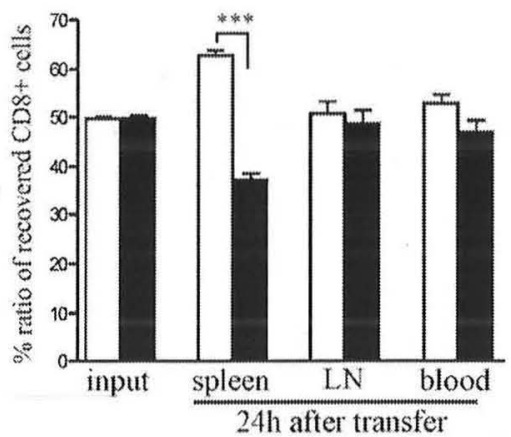

Fig. 4. Effects of social stress on cytokine secretion and migration capacity of $\mathrm{T}_{\mathrm{CD} 8+}$ splenocytes. (A) Splenocytes (SPL) or purified $\mathrm{T}_{\mathrm{CD} 8+}$ cells recovered on day 4 post-infection were stimulated for $24 \mathrm{~h}$ with plate-bound CD3/CD28 mAb. Supernatants were analyzed for IFN- $\gamma$ and IL-2 secretion by ELISA. Data are presented as the mean percentage of cytokine secretion of triplicate cultures \pm SEM. B-D) Homing pattern of $\mathrm{T}_{\mathrm{CD} 8}+$ cells from SDR and control mice after adoptive transfer. Equal numbers of sorted $\mathrm{T}_{\mathrm{CD} 8}+$ cells $\left(5 \times 10^{6}\right.$ cells) isolated either from LCMV-infected control (Thy-1.1) or SDR (Thy-1.2) mice were adoptively co-transferred into infected recipient mice (Ly5.1). Twenty-four hours after transfer, the ratio of donor-derived $\mathrm{T}_{\mathrm{CD} \text {, }}$ cells was analyzed in the spleen, $\mathrm{LN}$ and blood by flow cytometry. (B) Scheme of the experimental design. (C) Representative flow cytometric plots of recovered control (Thy1.2- Ly5.2 $2^{+}$) and SDR (Thy1.2 $2^{+}$Ly $5.2^{+}$) $\mathrm{T}_{\mathrm{CD} 8+}$ cells from indicated host (Thy1.2 ${ }^{+}$, Ly5.2-) organs are shown. (D) Data are presented as the ratio \pm SEM of recovered SDR to control $\mathrm{T}_{\mathrm{CD} 8}$ cells in the spleen, $\mathrm{LN}$, and blood. All graphs represent data from two independent experiments with a total of 10 mice per group.

comparable surface expression of CD44 and CD62L (day 2 and day 4 post-infection, data not shown). However, we found significantly lowered expression of the early T-cell activation marker CD69 on day 2 post LCMV-infection in SDR compared to control mice (Fig. 3D; SDR: $43.1 \pm 3.5 \%$ vs. control: $59.6 \pm 2.5 \%$ of $\mathrm{T}_{\mathrm{CD} 8+}$ cells).

\subsection{Glucocorticoids mediate the stress-induced decrease in $\mathrm{T}_{\mathrm{CD} 8+}$ cell expansion}

To identify the endocrine factors mediating the stress-induced decrease in $\mathrm{T}_{\mathrm{CD} 8+}$ cell expansion in the spleen, SDR and control mice were implanted with continuous release pellets containing either the glucocorticoid (GC) receptor antagonist RU486 or the $\beta$-adrenergic receptor antagonist nadolol. Unstressed control mice treated with RU486 or nadolol exhibited similar $\mathrm{T}_{\mathrm{CD} 8+}$ cell expansion in the spleen on day 8 of LCMV-infection compared to mice receiving placebo pellets (Fig. $3 \mathrm{E}$ and $\mathrm{F}$ ), demonstrating that neither of the two drugs influenced the LCMV-infection by itself. More importantly, splenic $\mathrm{T}_{\mathrm{CD} 8}$ - cell numbers in RU486-treated SDR mice did not differ from placebo- or RU486-treated control mice (Fig. 3E, SDR RU486: $49.2 \pm 1.3 \%$, control RU486: $51.3 \pm 2.3 \%$, control placebo: $51.1 \pm 1.5 \%$ ), indicating that treatment with the GC receptor antagonist completely abolished the stress-induced effects on $\mathrm{T}_{\mathrm{CD} 8+}$ cell expansion. In contrast, the frequency of $\mathrm{T}_{\mathrm{CD} 8+}$ splenocytes in nadolol-treated SDR mice was not significantly altered compared to placebo-treated SDR mice (Fig. 3F, SDR nadolol:
$35.2 \pm 2.4 \%$ vs. SDR placebo: $32.1 \pm 2.1 \%$ ), demonstrating that $\beta$ adrenergic receptor blockade was not effective in preventing the stress-associated changes of $\mathrm{T}_{\mathrm{CD} 8+}$ cell expansion in the spleen.

\subsection{Viral clearance}

To investigate whether the impaired generation of $\mathrm{T}_{\mathrm{CD} 8+}$ cells in the spleen resulted in an altered viral clearance, mice were infected with 200 pfu LCMV and virus titers were determined in the spleen of stressed and non-stressed mice on day 2 , day 4 , day 6 , and day 8 post-infection. Our results demonstrate that splenic viral titers were not altered at early time points of infection (day 2 and day 4 p.i.) in SDR mice (Fig. 3G). We noted for both groups an extensive decrease of the viral load during the later time course of the infection period (day 6 and day 8 p.i.). However, viral titers in the spleen of SDR mice were not significantly altered compared to control mice on day 8 p.i., although we noticed a tendency for enhanced virus titers among stressed mice (SDR: $18.5 \pm 7.4 \times 10^{3}$ pfu vs. control: $\left.5.6 \pm 1.2 \times 10^{3} \mathrm{pfu}\right)$.

\subsection{Social stress did not alter phenotype or antigen presentation of $D C s$ in the spleen}

Recent findings have suggested that glucocorticoids impair the competence of DCs to process and present virally expressed antigens, thereby altering their ability to activate $\mathrm{T}$ cells (Truckenmiller 
et al., 2006). Therefore we examined whether the reduced $\mathrm{T}_{\mathrm{CD} 8+}$ activation in SDR mice is the consequence of altered antigenpresentation in the spleen (Supplementary Fig. 1). However, SDR and control mice did not differ in the overall percentage of splenic $\mathrm{CD} 11 \mathrm{c}^{+} \mathrm{DCs}$ or $\mathrm{F} 4 / 80^{+}$macrophages during the early stage of LCMV infection (Supplementary Fig. 1A). Further analysis of the activation state of $\mathrm{CD} 11 \mathrm{c}^{+}$cells, analyzed by MHC class $\mathrm{I}\left(\mathrm{H}-2 \mathrm{D}^{\mathrm{b}}\right.$ and $\mathrm{H}-2 \mathrm{~K}^{\mathrm{b}}$ ) expression and CD80, CD86 surface expression revealed no differences between SDR and control mice (Supplementary Fig. 1B). To further address the possibility that splenocytes from SDR-mice present LCMV-derived epitopes less efficiently, we performed an ex vivo antigen-presentation assay. Splenocytes (day 4 post-infection) from SDR and control mice presented the LCMVderived GP33-41/D $/ \mathrm{K}^{\mathrm{b}}$ epitope to a similar extent, indicating that antigen presentation was not affected in SDR mice (Supplementary Fig. 1C). To exclude that the diminished $T_{\mathrm{CD} 8+}$ activation observed in SDR mice was due to some other functional defects of splenic antigen presenting cells to prime naïve T cells, we further analyzed the ability of pulsed GP33 splenocytes to stimulate naive GP33specific CTLs. GP33-pulsed splenocytes (day 4 post-infection) from control or SDR-mice could stimulate the GP33-specific CTLs to the same extend at all concentrations used (Supplementary Fig. 1D).

Since the proteasome is the key protease generating peptides for the MHC class I antigen presentation pathway, we hypothesized that SDR may impair the induction of the IFN- $\gamma$-inducible proteasome subunits LMP2, LMP7 and MECL1 thereby altering the repertoire of LCMV-peptides presented to CTLS (Groettrup et al., 2010). However, comparison of the subunit composition of the $20 \mathrm{~S}$ proteasome in livers of stressed and unstressed mice on day 8 of LCMV infection (Supplementary Fig. 2) revealed equal amounts of the subunits LMP2 and LMP7, thus demonstrating that the cellular content of the immunoproteasome was not altered. Taken together, our results provide evidence that the diminished $\mathrm{T}_{\mathrm{CD} 8+}$ splenocyte activation observed in SDR mice cannot be explained by an indirect mechanism via Ag-presenting DCs.

\subsection{Impaired secretion of IFN- $\gamma$ and IL-2 by $\mathrm{T}_{\mathrm{CD} 8+}$ splenocytes of stressed mice}

To elucidate whether the decreased $\mathrm{T}_{\mathrm{CD} 8}$, cell proliferation in SDR mice was attributable to an altered cytokine production, we further analyzed IFN- $\gamma$ and IL-2 secretion of splenocytes, and purified splenic $\mathrm{T}_{\mathrm{CD} 8}$ cells in response to anti-CD3/CD28 mAb stimulation. As shown in Fig. 4A, stimulated splenocytes from SDR mice showed a slightly decreased IFN- $\gamma$ (SDR: $1592 \pm 324$ vs. control: $2439 \pm 286 \mathrm{ng} / \mathrm{ml}$ ) and IL-2 (SDR: $154 \pm 28$ vs. control: $233 \pm 30 \mathrm{pg} / \mathrm{ml}$ ) secretion compared to splenocytes from control mice. More importantly, purified $\mathrm{T}_{\mathrm{CD} 8+}$ cells from SDR-mice demonstrated a significant reduction of IFN- $\gamma$ (SDR: $2089 \pm 240 \mathrm{vs.} \mathrm{con-}$ trol: $3153 \pm 394 \mathrm{ng} / \mathrm{ml}$ ) and IL-2 (SDR: $237 \pm 33$ vs. control: $428 \pm 52 \mathrm{pg} / \mathrm{ml}$;) secretion when compared with $\mathrm{T}_{\mathrm{CD} 8+}$ cells derived from control mice. Therefore we suggest that the limited in vivo $\mathrm{T}_{\mathrm{CD} 8+}$ proliferation is due to a lack of T-cell stimulating cytokines, particularly of IL-2 secretion.

The differential expression of the IL-7 receptor alpha chain (CD127) and the killer cell lectin-like receptor G1 (KLRG1) has recently been proposed as markers for virus-primed $\mathrm{T}_{\mathrm{CD} 8+}$ cells with distinctive functional capacities: short-lived effector cells (KLRG1 ${ }^{\text {high }}$ CD127 ${ }^{\text {low }}$ ) with high cytotoxic potential, and effector cells exhibiting high proliferative capacity that are destined to become memory cells (KLRG $1^{\text {low }} \mathrm{CD} 127^{\text {high }}$ ) (Voehringer et al., 2002; Kaech et al., 2003). Analysis of the expression profile of CD127 and KLRG1 on $\mathrm{T}_{\mathrm{CD} 8}$ + cells in the late stage of infection (day 8 postinfection) showed that the majority of $\mathrm{T}_{\mathrm{CD} 8+}$ cells exhibited a $\mathrm{KLRG}^{\text {high }} \mathrm{CD} 127^{\text {low }}$ effector phenotype. However, no differences with respect to CD127 and KLRG1 expression were observed be- tween SDR and control mice (data not shown), suggesting that the diminished effector cytokine secretion and replicative incapacity observed in SDR mice is not due to an altered $T_{C D 8}+$ cell differentiation fate.

\subsection{Effects of social stress on the homing capacity of splenic $\mathrm{T}_{\mathrm{CD} 8+}$} cells

Adoptive transfer experiments with magnetically purified T cells were performed to examine whether social stress altered the homing pattern of these cells. Equal numbers of infected control (Thy $1.2^{-}$, Ly5.2. $2^{+}$) and SDR (Thy $1.2^{+}$, Ly5.2 $2^{+}$) $\mathrm{T}_{\mathrm{CD} 8+}$ cells were mixed and i.p. transferred into infected Ly5.1 (Thy1.2+ ${ }^{+}$,y5 $5.2^{-}$) recipient mice (Fig. 4B: experimental design). Twenty-four hours after the adoptive transfer, the ratio of recovered donor-derived $\mathrm{T}_{\mathrm{CD} 8+}$ cells was analyzed in the spleen, LN and blood (Fig. 4C and D). Reduced frequencies of $\mathrm{T}_{\mathrm{CD} 8+}$ cells from SDR mice were recovered from the spleen (SDR: $37.4 \pm 1.2 \%$ vs. control: $62.6 \pm 1.2 \%$ ), whereas the frequency of adoptively transferred SDR $\mathrm{T}_{\mathrm{CD} 8}$ - cells towards the LN (SDR: $49.2 \pm 2.4 \%$ vs. control: $50.8 \pm 2.4 \%$ ) and the blood (SDR: $47.2 \pm 2.0 \%$ vs. control: $52.8 \pm 2.0 \%$ ) was not significantly altered compared to control $\mathrm{T}_{\mathrm{CD} 8+}$ cells. We further compared these results with intravenously transferred $\mathrm{T}_{\mathrm{CD} 8+}$ cells and found a lower ratio of recovered SDR to control $\mathrm{T}_{\mathrm{CD} 8}$ - cells in the spleen (SDR: $40.3 \pm 1.6 \%$ vs. control: $59.7 \pm 1.6 \% ; p \leqslant 0.001$ ) and blood (SDR: $43.1 \pm 1.3 \%$ vs. control: $56.9 \pm 1.3 \% ; p \leqslant 0.001$ ), whereas the frequency of recovered cells in the LN was not altered (SDR: $51.1 \pm 1.3 \%$ vs. control: $48.9 \pm 1.3 \%$ ). These results demonstrate that effector $\mathrm{T}_{\mathrm{CD} 8+}$ cells from SDR mice exhibit a decreased homing to the spleen compared to effector $\mathrm{T}_{\mathrm{CD} 8+}$ cells from control mice. In contrast, we found no major alterations in the migratory capability of naïve $\mathrm{T}_{\mathrm{CD} 8+}$ cells isolated from non-infected SDR mice (data not shown), suggesting that the altered homing capacity of $\mathrm{T}$ cells is a specific feature of SDR effector $\mathrm{T}_{\mathrm{CD} 8+}$ cells and not due to an overal change in the migratory behaviour of $\mathrm{T}_{\mathrm{CD} 8+}$ cells after social disruption stress.

\section{Discussion}

The present study demonstrates that chronic social stress compromises the $\mathrm{T}_{\mathrm{CD} 8}+$ cell-mediated response to LCMV-infection. When mice were exposed to a 6-day social disruption procedure, we noted a significant reduction of IFN- $\gamma$ producing $\mathrm{T}_{\mathrm{CD} 8}+$ cells in the spleen on day 8 post-infection, indicating that social stress profoundly impairs the function of $\mathrm{T}_{\mathrm{CD} 8+}$ cells by inhibiting antigenspecific IFN- $\gamma$ secretion. Therefore, we further determined plasma levels of IFN- $\gamma$ in mice throughout the course of LCMV infection. We found that on day 6 post-infection, when levels of IFN- $\gamma$ were maximal in the control group, SDR mice showed an almost $50 \%$ reduction in circulating IFN- $\gamma$ (Fig. 2E). These results support previous reports, demonstrating that social stress alters the production of pro- and anti-inflammatory cytokines including IFN- $\gamma$, TNF- $\alpha$, and IL-10 (Merlot et al., 2004; Avitsur et al., 2005). Interestingly, these alterations were only found when the stress procedure was applied prior to virus infection, whereas LCMV infection at the onset of the stress procedure had only marginal effects on the CTL response. These observations are compatible with recent reports demonstrating that SDR exacerbates the pathophysiology of Theiler's virus infection (Johnson et al., 2004, 2006) and BCG-infection (Merlot et al., 2004) when the stress was applied prior but not concurrently with infection. These data are in line with the insight that priming of $\mathrm{T}$ cells occurs during the first two days after virus encounter, i.e. at a time point when stress-related immune suppression needs to be established in order to show strong effects. 
Prolongation of the SDR procedure for three additional days after LCMV infection led to a profound reduction of $\mathrm{T}_{\mathrm{CD} 8+}$ cells in the spleen of SDR-treated mice on day 6 and day 8 post-infection. In contrast, there were no differences in the $T_{C D 8+}$ population on day 2 and day 4 after infection, indicating that a modulation of $\mathrm{T}_{\mathrm{CD} 8+}$ population occurs during the antigen-driven $\mathrm{T}$ cell expansion phase and is not due to initially reduced $\mathrm{T}_{\mathrm{CD} 8}$, cell numbers. While a comparison of apoptotic cells revealed no differences between SDR mice and non-stressed control mice we found that on day 5 of infection, when the expansion of LCMV specific $\mathrm{T}_{\mathrm{CD} 8+}$ cells is most vigorous, the proliferation of $\mathrm{CD}^{+}$cells was significantly reduced by $28 \%$. These in vivo results extend previous reports on suppressed in vitro proliferation of $\mathrm{T}$ cells upon ConA stimulation (Merlot et al., 2004) and diminished proliferation of lymphocytes caused by restraint stress (Tournier et al., 2001).

We assumed that the reduced $\mathrm{T}_{\mathrm{CD} 8+}$ proliferation is probably accompanied by inefficient $\mathrm{T}$-cell activation. Indeed, we found significantly lowered expression of the early T-cell activation marker CD69 on day 2 of LCMV-infection in SDR mice compared to the control group (Fig. 3D), while other activation markers, like CD44 and CD62L, were not affected. Cross-linking studies have suggested a role for CD69 in regulating IL- 2 and IFN- $\gamma$ production, enhancement of IL-2 receptor (CD25) expression, and IL-2-dependent T cell proliferation (Ziegler et al., 1994). Therefore, the stress-induced perturbation of $\mathrm{T}$ cell proliferation is likely initiated by an early disturbance of $\mathrm{T}_{\mathrm{CD} 8}+$ activation.

Previous studies have shown that glucocorticoids modulate the Ag-presenting capability of dendritic cells (DCs) by altering their maturation (Moser et al., 1995; Matyszak et al., 2000; Elftman et al., 2007; Powell et al., 2009), MHC surface expression (Elftman et al., 2007), and the formation of MHC-antigen complexes (Truckenmiller et al., 2006, 2005). Therefore, we examined the possibility that the reduced $\mathrm{T}_{\mathrm{CD} 8+}$ activation in SDR mice is the consequence of altered antigen-presentation in the spleen. However, SDR and control mice did not differ in the overall percentage of splenic $\mathrm{CD} 11 \mathrm{c}^{+} \mathrm{DCs}$ or $\mathrm{F} 4 / 80^{+}$macrophages throughout the early stage of LCMV infection. Furthermore, DCs from SDR mice expressed similar levels of costimulatory and MHC class I molecules compared to control mice, suggesting that stress did not affect the maturation process of DCs in vivo. Applying an ex vivo antigenpresentation assay, we could also exclude the possibility that APCs derived from SDR mice exhibit an impaired efficiency of MHC class I antigen presentation. The discrepancies to previous results are likely due to different experimental approaches, namely the application of exogenous GCs in contrast to the more complex secretion of endogenous GCs during the physiological stress response. However, these latter findings indicate that the diminished $\mathrm{T}_{\mathrm{CD} 8}$ splenocyte activation observed in SDR mice could not be explained by an indirect mechanism via Ag-presenting DCs.

To identify the endocrine factors mediating the stress-induced decrease of $\mathrm{T}_{\mathrm{CD} 8+}$ cell expansion in the spleen, mice were either treated with the GC receptor blocker RU486 or the $\beta$-adrenergic receptor antagonist nadolol. We found that in vivo blockade of $\mathrm{GC}$ receptors completely abrogated the stress-associated $\mathrm{T}_{\mathrm{CD} 8+}$ cell decline in the spleen of SDR mice. In contrast, treatment of SDR mice with nadolol resulted in a $\mathrm{T}_{\mathrm{CD} 8+}$ cell reduction similar to that obtained from placebo-treated SDR mice, suggesting that the reduction in $\mathrm{T}_{\mathrm{CD} 8}+$ cell numbers was not related to systemic increases of the catecholamines adrenaline and noradrenaline. In conclusion, these data strongly indicate that suppression of $\mathrm{T}_{\mathrm{CD} 8+}$ cell expansion in response to stress is mediated by glucocorticoid hormones.

Taken together, this study provides novel evidence that social stress negatively influences the primary immune response to LCMV-infection characterized by a reduced number of IFN- $\gamma$ producing $\mathrm{T}_{\mathrm{CD} 8+}$ cells as well as profoundly decreased expansion of activated $\mathrm{T}_{\mathrm{CD} 8+}$ splenocytes in case of a prolonged stress exposure. We propose a mechanism whereby glucocorticoids inhibit cytokine production and proliferation of $\mathrm{T}_{\mathrm{CD} 8}$ cells thereby altering their functional capacity. In conclusion, our data imply that social stress is associated with a profound suppression of $T$ cell function, which may represent a key factor in the increased susceptibility of socially stressed individuals to viral infections.

\section{Conflict of interest}

The authors declare no financial or commercial conflict of interest.

\section{Acknowledgments}

We would like to thank Bernd Kress for his excellent technical assistance. This work was supported by grants from the German Research Foundation, Research Group FOR 751, Project B1 (GR 1517/6-1 and EN 814/1-2).

\section{References}

Avitsur, R., Stark, J.L, Sheridan, JF, 2001, Social stress induces glucocorticoid resistance in subordinate animals. Horm. Behav. 39, 247-257.

Avitsur, R., Kavelaars, A., Heijnen, C., Sheridan, J.F., 2005. Social stress and the regulation of tumor necrosis factor-alpha secretion. Brain Behav. Immun. 19, 311-317.

Basler, M., Moebius, J., Elenich, L., Groettrup, M., Monaco, J.J., 2006. An altered T cell repertoire in MECL-1-deficient mice. J. Immunol. 176, 6665-6672.

Battegay, M., Cooper, S., Althage, A., Banziger, J., Hengartner, H., Zinkernagel, R.M., 1991. Quantification of lymphocytic choriomeningitis virus with an immunological focus assay in 24- or 96-well plates. J. Virol. Methods 33. 191-198.

Bonneau, R.H., 1996. Stress-induced effects on integral immune components involved in herpes simplex virus (HSV)-specific memory cytotoxic $\mathrm{T}$ lymphocyte activation. Brain Behav. Immun 10, 139-163.

Bonneau, R.H., Sheridan, J.F., Feng, N.G., Glaser, R., 1991a. Stress-induced effects on cell-mediated innate and adaptive memory components of the murine immune response to herpes simplex virus infection. Brain Behav. Immun. 5, 274-295.

Bonneau, R.H., Sheridan, J.F., Feng, N.G., Glaser, R., 1991b. Stress-induced suppression of herpes simplex virus (HSV)-specific cytotoxic T lymphocyte and natural killer cell activity and enhancement of acute pathogenesis following local HSV infection. Brain Behav. Immun. 5, 170-192.

Elftman, M.D., Norbury, C.C., Bonneau, R.H., Truckenmiller, M.E., 2007. Corticosterone impairs dendritic cell maturation and function. Immunology 122, 279-290.

Engler, H., Bailey, M.T., Engler, A., Sheridan, J.F., 2004. Effects of repeated social stress on leukocyte distribution in bone marrow, peripheral blood and spleen. J. Neuroimmunol. 148, 106-115.

Engler, H., Engler, A., Bailey, M.T., Sheridan, J.F., 2005. Tissue-specific alterations in the glucocorticoid sensitivity of immune cells following repeated social defeat in mice. J. Neuroimmunol. 163, 110-119.

Gallimore, A., Dumrese, T., Hengartner, H., Zinkernagel, R.M., Rammensee, H.-G., 1998. Protective immunity does not correlate with the hierarchy of virusspecific cytotoxic T cell responses to naturally processed peptides. J. Exp. Med. 187, 1647-1657.

Groettrup, M., Ruppert, T., Kuehn, L., Seeger, M., Standera, S., Koszinowski, U., Kloetzel, P.M., 1995. The interferon-g-inducible $11 \mathrm{~S}$ regulator (PA28) and the LMP2/LMP7 subunits govern the peptide production by the $20 \mathrm{~S}$ proteasome in vitro. J. Biol. Chem. 270, 23808-23815.

Groettrup, M., Kirk, C.J., Basler, M., 2010. Proteasomes in immune cells: more than peptide producers? Nat. Rev. Immunol. 10, 72-77.

Johnson, R.R., Storts, R., Welsh Jr., T.H., Welsh, C.J., Meagher, M.W., 2004. Social stress alters the severity of acute Theiler's virus infection. J. Neuroimmunol. $148,74-85$.

Johnson, R.R., Prentice, T.W., Bridegam, P., Young, C.R., Steelman, A.J., Welsh, T.H., Welsh, C.J., Meagher, M.W., 2006. Social stress alters the severity and onset of the chronic phase of Theiler's virus infection. J. Neuroimmunol. 175, 39-51.

Kaech, S.M., Tan, J.T., Wherry, E.J., Konieczny, B.T., Surh, C.D., Ahmed, R., 2003. Selective expression of the interleukin 7 receptor identifies effector CD8 T cells that give rise to long-lived memory cells. Nat. Immunol. 4, 1191-1198. 
Matyszak, M.K., Citterio, S., Rescigno, M., Ricciardi-Castagnoli, P., 2000. Differential effects of corticosteroids during different stages of dendritic cell maturation. Eur. J. Immunol. 30, 1233-1242.

Merlot, E., Moze, E., Dantzer, R., Neveu, P.J., 2004. Immune alterations induced by social defeat do not alter the course of an on-going BCG infection in mice. Neuroimmunomodulation $11,414-418$

Merlot, E., Moze, E., Dantzer, R., Neveu, P.J., 2004. Cytokine production by spleen cells after social defeat in mice. activation of $\mathrm{T}$ cells and reduced inhibition by glucocorticoids. Stress 7, 55-61.

Moser, M., De Smedt, T., Sornasse, T., Tielemans, F., Chentoufi, A.A., Muraille, E., Van Mechelen, M., Urbain, J., Leo, O., 1995. Glucocorticoids down-regulate dendritic cell function in vitro and in vivo. Eur. J. Immunol. 25, 2818-2824.

Powell, N.D., Bailey, M.T., Mays, J.W., StinerJones, L.M., Hanke, M.L., Padgett, D.A Sheridan, J.F., 2009. Repeated social defeat activates dendritic cells and enhances Toll- like receptor dependent cytokine secretion. Brain Behav. Immun. 23, 225-231.

Sheridan, J.F., Stark, J.L., Avitsur, R., Padgett, D.A., 2000. Social disruption, immunity. and susceptibility to viral infection: role of glucocorticoid insensitivity and NGF. Ann. NY Acad. Sci. 917, 894-905.

Stark, J.L., Avitsur, R., Padgett, D.A., Campbell, K.A., Beck, F.M., Sheridan, J.F., 2001 Social stress induces glucocorticoid resistance in macrophages. Am. J. Physiol. Regul. Integr. Comp. Physiol. 280, R1799-R1805.

Stefanski, V., Peschel, A., Reber, S., 2003. Social stress affects migration of blood T cells into lymphoid organs. J Neuroimmunol. 138, 17-24.
Tournier, J.N., Mathieu, J., Mailfert, Y., Multon, E., Drouet, C., Jouan, A., Drouet, E, 2001. Chronic restraint stress induces severe disruption of the T-cell specific response to tetanus toxin vaccine. Immunology $102,87-93$.

Truckenmiller, M.E., Princiotta, M.F., Norbury, C.C., Bonneau, R.H., 2005. Corticosterone impairs MHC class I antigen presentation by dendritic cells via reduction of peptide generation. J. Neuroimmunol. 160, 48-60.

Truckenmiller, M.E., Bonneau, R.H., Norbury, C.C., 2006. Stress presents a problem for dendritic cells: corticosterone and the fate of MHC class 1 antigen processing and presentation. Brain Behav. Immun. 20, 210-218.

van der Most, R.G., Murali-Krishna, K., Lanier, J.G., Wherry, E.J., Puglielli, M.T., Blattman, J.N., Sette, A., Ahmed, R., 2003. Changing immunodominance patterns in antiviral CD8 T-cell responses after loss of epitope presentation or chronic antigenic stimulation. Virology 315, 93-102.

Voehringer, D., Koschella, M. Pircher, H., 2002. Lack of proliferative capacity of human effector and memory T cells expressing killer cell lectinlike receptor G1 (KLRG1). Blood 100, 3698-3702.

Ziegler, S.F., Ramsdell, F., Alderson, M.R., 1994. The activation antigen CD69. Stem Cells 12, 456-465. 